\title{
Effective Assessment: A Challenge to Succesful Implementation of Performance Lag Address Programme. The Case of Primary Schools in Gutu North Zvavahera Cluster of Zimbabwe.
}

\author{
Samuel Masomera
}

\author{
Emily Ganga
}

\begin{abstract}
The Performance Lag Address Prgramme(PLAP) is a teaching strategy aimed at addressing gaps and challenges of learners in mastering concepts being taught by initially going back to their last point of success.Low academic pass rate in primary and secondary schools influenced researchers and academics to come up with a strategy which specifically address individual challenges of learners and enhance academic performance through individualised instruction.However,effective assessment continues to be a challenge to many teachers. The research sought to investigate the the problems posed by the lack of effective assessment of the implementation of PLAP.The study was conducted in Gutu North Zvavahera Cluster involving 25 particpants from six schools.Data was collected through indepth interviews, focus group discussions and document analysis of teachers' PLAP record books to complement findings from interviews and FGDs.The found oput that effective assessment is a challenge in the effective implementation of PLAP.The Wide Range Achievement Test was criticised of not giving teachers adequate insight on the real problems facing learners.Teachers highlighted that they are not fully equipped and lack required btechinical know how of using various assessment methods beside tests. The recommended format of recording PLAP was seen to be vague assessment and communicating elaborately the performance of the learners.The researchers recommended tha the edcuation system should prioritise assessment as a major component of the teaching and learning process by providing skills and material support to teachers.District offices should have expert teachers on effective assessmnet who help teachers in using multiple assessment methods and realise the benefit of doing so.
\end{abstract}

\section{INTRODUCTION}

Assessment is a multi disciplinary process which draws information from teachers,pupils and even parents. The child's parents can provide valuable information about a child,how best the child learns and the asessment preferences available basing on hints from the parents.The knowledge and practice of assessment continues to be elusive despite numerous publications and researches available.Assessment is a process of collecting, analysing and interpreting evidence and using it to make inferences about what pupils know and can do (Harlen,2012).Dockrele and McShane (1995) state that assessment is a way of examining individual characteristics that are important for estabilishing individual intervention programs.Remedial and extension, special classes have been used in zimbabwe primary schools to assist learners with special needs however, low pass rates in consecutive years after the dollarisation of the economy has prompted researchers and academics to seek a broad based system of addressing low achievement in schools.The Irish National Council for Curriculum and Assessment(NCCA)(2014) say assessment is used to identify children with learning difficulties so that the nature of the support and assisstance they need can be ascertained and appropriate strategies and programming put in place to enable them to cope 
with particular difficulties.However, the inclination to the fact that learning problems are as a result of poor instruction or the lack of it ignores the fact that even children have their special ways of learning whcih neeed to be ascertained first.

Multiple assessment tools have been thought to complement each other and bring a holistic judgement of the performance of the child.However, teachers continue to over rely on tests.Testing has been found to be meritorious in saving time, efficient in covering the syllabi,easy to conduct and assess pupils. However, over reliance on testing results in invalidity blocks which could be cleared by the use of multiple asessment tools by the teacher(Mansell and James,2009).One cannnot solely depend on tests to assess pupils because it overlooks individual differences in learner preferences and multiple intelligences.The Global Education Association (2011) say there is need to use multiple measures to assess and report on the progress of learners for accountability purposes such as curriculum- based, performance based and holistic assessment using scoring guides,checklists and rubrics.The association also recommends an adoption of a learning for mastery model of asessment where learners are allowed to resubmit and retake tests.Ginsberg and Woldowski (2009) argue that effective asessment utilises multiple and varied methods of student performance evaluation.Assessment should be an on-going and spontaneous activity where teachers compile information about their pupils during class and out of class.Mansell and James(2009) say it is appropriate for teachers to simply record their judgements of pupils' during day to day classroom work and review these at appropriate intervals to come to a summing judgement.Thompson (1981) insinuates that diversity in assessment benefit students when they construct and submit test questions for possible inclusion in exams since this increases intrinsic motivation,decreases test anxiety by increasing the sense of percieved control of the test situation.

Teachers in rural schools seem not to be well conversant with the use performance assessment in classes and their learners continue to be deprived of the motivational properties of this type of assessment. Omidi;Sridha, Azizmalayeri (2012) research on the impact of performance assessment found ot that there is a significant influence of performance assessment on academic achievement, in traditional assessment group learnes scored significantly lower than learners who were in performance assessmentt group.Teachers in primary schools need to accompany tests w'ith performance assessment as learners can be motivated by performance assessment.Performance assessment is an active learning experience and actually motivates students to learn more about the subject matter, they demonstrate knowledge and understanding through performance (Omidi,et al, 202).The research intends to highlight the fact that it is meritoriuos to use multiple assessment tools to ensure thye implementation of any intetrvention strategy in the educatiuon system.

Classroom assessment is the most important type of asessment since it gives an indication of the level of performance of a child in high stakes examinations like the grade seven examinations.Mansell and James (2009) say the nature and impact of assessment depends on the uses to which the results are put hence a system whose priority is to generate information for internal use by teachers on the next steps of pupils learning must have different characteristics and effects.Kurebwa and Nyaruwata (2012) cites Hurly and Tinajoro (2001) who say that classroom assessment is seen as helpful because it gives a more immediate measure of progress and achievement of students, guides and improves instruction and diagnosises student knowledge of a topic. Through assessment the teacher constructs a comprehensive picture of the short term needs of the child and plans future work accordingly(NCCA, 2014).Teachers usually use weekly test and fortnightly tests to assess pupils to fulfill departmental or school policies but do not give much thought on the 
implications of the results. Assessment for learning is usually formative and is a process which seeks and interprets evidence for use by learners and their teachers to decide where the learners are in their learning, where they need to go and how best to get there (Mansell and James,2009).Teachers generally use testing due to its time and cost effectiveness however researchers have found weaknesses in over relying on testing.Joughin(2010) in Omid et al (2012) says asssessment tasks must be part of the regular teaching and learning program hence is believed to drive student achievement.

The effectiveness of an instrument is measured on how it produces the required results,it entails the clarity, pragmatic and worthwhileness of the results.Assessment of primary school children should provide the correct,informative and valuable information to teachers and parents need about a learner, group,class or stream.The method of collecting that information should be understood by all participants hence teachers,children and parents.Stepanek (2002) in Sususwele-Banda (2005) says when teachers place meaningful assessment at the centre of instruction, they give students insights into their own thinking and growth, and students gain new perspectives in their potential.Susuwele-Banda (2005)says the shift from assessing students' achievement to assessing how they are learning helps the teacher to explore better ways of supporting the student to learn better.It may not be that learners missed a lot of learning time when teachers were absent or on industrial action because even leaners who started school after the dollarisation of the economy still have problems in academic achievement. As a result ,this points to the fact that learners have their inherent perculiar learning styles which need to be assessed first to ensure meaningful learning.Kurebwa and Nyaruwata(2012) report that researches show that teachers hardly used variety of instruments such as tests, class work, observations, questionnnires, reports, checklists,rating scales inventory and practicals.Fennel et al (1992) cited in Susuwele-Banda (2005) suggest that specific training is necessary for teachers to learn to assess childrens' thinking.It is a recipe for disaster if teachers continue to shun other emerging methods of assessment.

The Wide Range Achievement Test is used by teachers in identifying the last point of success of learners hence the grade level they are performing at in English and Mathematics.Kaputa (2009) says WRAT is generally accepted as convinient and sufficient for identification purposes since it provides scores in reading, spelling and arithmatic. The scores can be indicated in terms of grade equivalent,standard score or percentile. However the grading sytsem used in WRAT does not communicate useful information to students about their weak areas.Language does not occur in fragments such as words but as passages and sentences that communicate meaning. Really WRAT cannot be the only assessment tool to be used to assess the learners because teachers are known to have negative perceptions of stratgies that a dictatated from the top. WRAT overlooks fundamental difficilties in comprehension, creative writing, intrpretation of story mathematical problems which a ramapant in many rural primary school classrooms.WRAT is effective for leaners in Western countiries because the medium of instruction is their mother tongue while learners in Africa, English is a second language and is learnt and this puts them in a compromising position.Since English is taught some teachers drill phonemes to the extend that some learners can read any word which they no nothing about its meaning and how to use it.WRAT is devorcd from the nature of assessmentused in high stakes tests hence does not provide useful information other than the grade level.Gearheart and Litton(1975) say considering errors in the construction of tests,measurement errors,the generally presumed cultural bias one cannot rely on one assessment tool.The greatest challenge which is even faced by teachers in rural areas is that learners have problems in interpreting questions, have difficult in aplying what they learnt to 
Masomera, S., \& Ganga, E. (2015). Effective Assessment: A challenge to Successful Implementation of Perofrmance Lag Address Programme. The Case of Primary Schools in Gutu North Zvavahera Cluster of Zimbabwe. Advances in Social Sciences Research Journal, 2(12) 117-125.

answer questions and in worse scenarios remember what they actually learnt. It is every teacher's wish to find solutions to these problems and PLAP may not have dealt with the challenges intricately as expected.

Effective asessment for the implementation of PLAP could have include a check list which sought to provide a holist assessment of the child's skills competences and challenges. Adamson (1979) in Kaputa ((2009) provides key problems learners which teachers and parents need to assess so that they can best assisst the learners.

$\sim$ Conceptualisation problems - learners may have problems in abstract reasoning, reading comprehension and inferential thinking;

$\sim$ Language - language development and problems in sequencing, preservation, syntax and written expression;

$\sim$ Memeory- variation in immediate and remote auditory visual and associated recall;

$\sim$ Feeling of inadequacy (hurt $\backslash$ pride)- poor self concept,low self esteem, negative body image;

$\sim$ Task avoidance behaviuor- avoidance of learning tasks which are difficult and subject to exposure failure.More off task behaviour for example taking too long to sharpen a pencil (Adamson, 1979 in Kaputa , 2009).

The learners in rural primary schools have poor handwriting,poor word recognition, poor vocabulary, low comprehension skills, inferential skills, poor sentence construction, among other challenges in English.In mathematics basic operations are difficult while application of formulae is even worse.Assessment processes should be centered on measuring the performance of learners in these areas and diagnosing different learning challenges.Sgroi (1995) in Susuwele-Banda(2005) believes that assessment to monitor students' understanding of mathematics concepts is very critical and classrooms should be organised to promote active participation of students.

The challenges facing primary schools especially those in rural areas are many and very complex. It is upon researchers and academics to come up with strategies which best apply to the perculiar problems faced by primary school teachers in their quest to improve academic pass rates at their schools.Among other challenges, primary schools face shortages of teaching and learning materials and experienced teachers. The state of primary education depreciated to astounding levels since the turn of the millenium due to the economic hardships that Zimbabwe experience. The hyper inflation and devaluation of the Zimbabwean dollar forced teachers out of classes and forced them on the exodus to neighbouring countries looking for greener pastures. Mufanechiya and Mufanechiya (2011) report that the economic challenges devalued education,even parents mocked the profession, absenteeism and drop-outs reached an all -time high.Schools were left on a standstill as they were unmanageable for the school heads and authorities.Many children did not go to school for nearly a year between 2008 and 2009 and Grade 7 national pass rates drooped to below 20\% and many schools recorded 0\%.

Schools were later opened in February 2009 and teachers were paid through vouchers in American Dollars. The money was not enough and trade unions battled with government over salary increases however the fi scus could not sustain an increasd wage bill.The education minister introduced the controversial teacher incentives which had to complement the government salaries. However, teachers in rural areas cried foul as their schools could not afford the same amounts paid by boarding and urban schools. The incentives were dropped and teacher motivation dropped also.Pass rates continue to be lower in rural areas than in urban areas. Researches have shown that learners in rural areas faces many challenges chief 
among the absenteeism and lack of schools fees. Poverty continues to be high in rural areas as the US Dollar is difficut to come by to the rural folk.

Parents in rural areas find it difficult topay their school fees due to poverty.Chikwanha- Dzenga (1999) say that unemloyment and dependance syndrome are the causes of poverty in rural areas.Chindanya (2011) says lack of fees cause parents not to be involved in the learning of their children.A parent who does not value the education of the child is likely to absent the learner from school for no apparent reason.Absenteeism creates gaps in the learning procees which causes failure.Gaps in the understanding of a concept limit the child's level of mastery.

The Ministry of Primary and Secondary Education launched the Performance Lag Address Programme (PLAP) in Mutare in in 2013 to address the challenge of low pass rates in the province.The same programme was rolled out in various district in the country.Nkoma (2014) expalins that PLAP is a result of a deep-stick evaluation which entailed assessing the teacher learning process,teacher-pupil records,resources provision and monitoring and evaluation programs. PLAP is a form of remediation that teachers have been doing all along.However ,PLAP is the universal and mainstreamed type of remediation.PLAP also takes care of exceptional who can be found to be above the grade level they are curently in where the teacher provides instruction to cater for those learner.Mukoko and Mdlongwa (2014) say students' weakness are believed to have cropped up from concepts missed at lower levels thus affecting their present performance hence the teacher has to address thses problems as a class so that learners can catch.In this era, focus should be on how learners learn and how best thyey can be taught. Learners ihave differences in how they learn and rtespond to different assessment tool.

The assumption that learning ga were created only by the absence of teachers ,learning material due to the harsh economic environment experienced between 2000 to 2009 overlooks fundamental issues.Teachers are not wholly to blame for their lack of comitment when all social service crumpled.The teacher training, curriculum review and research were also hit by the general exodus of critical personnel to neighbouring and overseas destinations which provided better remuneration and working conditions.It is apparent bthat teachers who graduate from colleges and universities may not have been fully equipped with the necessary knowledge and skilss in the use of assessment methods.Susuwele-Banda (2005) cites Dean (1991) who contends that most teacher education skim over classroom assessment, leaving teachers to assss in the same way they were assessed when they were at school.Campbell aand Evans in Susuwele-Banda (2005) evaluated pre-service teachers who had completed course work in educational measurement and found that studentbteachers did not follow assessment practises recommended in their course work.One is incliend to say teacher training is not effectively traing teachers on how tob assess while teachers are so autonomous that they do as they please when they arebin their classrooms. Hence aholistic view to these circumstances enable a deeper and balanced search for solutions.For instance some learner with poor performance started rimary education during the Eduation Transition Fund so the earlier accusation does not stand.

\section{RESEARCH QUESTIONS}

The research was guided by the following research questions;

- Is the assessment system used in schools effective in implementing the Performance Lag Address Programme?

- What can be done to improve the quality of assessment in primary schools? 


\section{METHODOLOGY}

The research followed a qualitative reseacrh design.Joubish,Khurram,Ahmed,Fatima and Haider (2011) say qualitative research is used to help us understand how people feel and why they feel as they do by collecting in-depth information through open ended questions'in naturastic setting to produce detailed data that allow direct qoutations.The qualitaive design is meritorious in that it uses human insight and experience,gives a deeper understanding of the research object(Joubish et al,2011). Patton and Cochran(2002) support that qualitative research is characterised by its aims, which relate to understanding some aspect of social life and its methods which generate words of analysis. The research used a qualitative case study which hich could provide an indepth analysis of the nature of assessment and its impact on PLAP.Bell (1994) says qualitative case studies allows the researcher to concentrate on a specific instance or siytuation,analyse varous interactive processes at work and its cost and time effective.The resarcher used indepth interviews ,focus group discussions(FGDs) and document analysis of plap documents to collect data which was analysed through thematic contetnt analysis. From a population of 94 teachers and 6 school heads the reseachers purposively sampled 5 school heads and conviniently sampled 25 teachers to participate in the research.

\section{DATA COLLECTION PROCEDURES}

The researchers acquire authorisation to collect data from the Provincial edication director and Gutu District Education Officer.The researchers visited school and presented the school heads with letters of approval and audio taped FGDs and interviews which were later transcribed and analysed.A checklist was used for document analysis on teachers' PLAP record books.

\section{FINDINGS AND DISCUSSION}

Findings ffrom interviews and FGDs idicated that WRAT does not provide teachers with adequate information of the nature of gaps in the learning of pupils.Kaputa (2009) expalins that WRAT is effective and sufficeient for identification pruposes .However findings from bothe interviews and FGDs showed that teacjhers were critical about thye manner in which the WRAT was adminstered since learners were not given enough time ti prepare for the test and did not understan the implications of the results of the exercise. Some teachers agrued that even parents had the right to be sensitised about the programme because some parents were asking why their children were given exercises of previous grades.Cook -Gumperz (1986) says problems such as cultural values, anxiety, test sophistication and the language ussed for giving instructios are rarely taken into account yet viot is known that applying tests that are verbally loaded to individuals who are learning english as a second language compounds the problems of adequate assessment.One is inclined to say tha pupils were not effectively assessed to ensure successfull implementation of PLAP. PLAP is a programme that seeeks to go deeper that just identification ,teachers need informations of the nature of problems hence $80 \%$ of teachers who were interviewed highlighted the fact that a criterion refertenced tests needed to accompany WRAT so that they get a clear picture of the challenges learners have ."At the beginning of every topic teachers need to give a diagnostic tests which will give them an idea of bthe nature of challenges learners have especially in Maths," explained one teacher in a FGD.Schools heads were critical of using WRAT and preferred locall designed teats because the WRAT was bdesigned for foriegn learners which a com,pletely diffrent from learners in rural areas of Zimbabwe.Litton (1975) indicates that tests such as the WRAT have cultural bias.Zindi (1994) quotes Laosa (1977) that, "Standardised tests are biased and unfair bto persons from cultural and socio-cultural minorities since most tests reflect largely white, 
middle-class values band attitudes and they do not reflect the experiences and the linguistic,cignitive and cultural styles and values of minority group persons"

Findings from the three instruments indicate that the assessment system currently being used in schools is rigid,highly structured and gives no room for teacher creativity and innovation.Teachers have been using the same way of assessing pupils since they graduated from training institutions.80\% who participated in the research indicated that assessment continue to be very unclear to them as they said assessment is the same as testing.When the said assessment they mean testing whereas testing is subsumed in assessment.Dikli (2003) explqins that assessment is the collection of information about what learners have mastered in the learning process while testinmg is usually formall,standardised bway of measuring student performance.PLAP's main principle is on m,atery of learning hence the evaluations are bases $\mathrm{n}$ mastery and no-mastery basis.It is apparent that tests alone cannot provide enough information bout the learners. Mansen and James (2009);Ginsberg and Woldowski( ) concide on tyhe idea that effective assessment becomes successfull throughj the use of multiple methods of assessment like performance bsed assessment,portifolios and projects among others.

The findings from documenta analysis of teachers record books of PLAP show that teachers adhere to the format that is contained in the teachers manual.No adaptations have been made in as far as improving the effectiveness of tyhe programme since it is currently under initial implimantation.However, the eveluation of the pupil performance is indicated by 'Mastered' and 'Not Mastered' and Remediation was seen as the only way teachers cater for learner with problems in the content coverd.Of concern, is the fact that teachers indicate that most of the pupils masterd the concepts.The validity of the evaluaion become questionable and give the impression that teachers write the records at home just to fulfill beuaracratic demands.A process of addressing perofrmance gaps in learners cannot be judged by one a few words of symbols like 'M' mastered and 'NM' for not mastered.There is need for a full description anmd judgement of learner performance which fully reflect the progress being made by the leaner and envisage the teacher's effort.

The majority of teachers in focus group discussions indicated that they cannot fully assess pupils because they do not have the teachers bmanual for the implemenation of PLAP hence do not know sopme of the suggested assessment methods.Teacher s repoerted that they use teats beacause of time concerns snce the district directirate counts the number of exercises written per week hence teachers are preoccupied with fufilling that demand."We are suffering yet they continued to pour more work on us,we jus don have the time for those tricks,we are always tired and we just fill inn the records so that the headmaster can stamp." The researcher found a glaring reality of negativity in taechers about the whole programme of PLAP a

The school heads hold the view that teachers were not fully trained in the implementation of of PLAP since PLA cluster focal teachers were trained for only two days at the district offices and thy then facilitted a one-day workshop to teachers from the six school who later cascaded the information to their schools. The teachers recived fourth hand information on the implementation of PLAP hence there were bound to be problems.However, the cluster chairperson in an interview higjhlighted the fact that the programme is well funded hence more workshops were in pipeline. 
Findings from focus group discussions indicated thatteachers from teachers college do not eel that they are fully equipped in using other assessment methods.They emphasised the fact that they are not fully grounded on alternative methods of assessment.Teacher training istitutions were blamed for failing to be thorough in taeching courses in effective assessment.

Findings from FGDs showed that teacher use forghtnightly and end of term tests to assess their pupils.The teachers argued bthat the district directorate is pressurising teachers to increase academic pass rates and those who fail are forced to submit their record books to trhe district every week bas puniotive measure.As a result teachers are afraid of having low pass rates at their schools so the continue to drill their pupils for examinations."Some have to cheat in examinations because they cannot afford to fil to reach the targeted percentage pass rates." In this ciurrent scenario, bthe quality of assessment bis compromised and learners are not allowed to master concepts but to memorise.

School heads bemoaned the fact that there seems to be no laid down framework on the use of alternative assessment methods hence it is difficult or school heads to supervise teachers when the use other assessment methods beside tests."Very few teachers know how to use other assessment methods but even if they do how bwill the record it.We were never taught the format of using contiuous assessments other methods." highlighted one of the teachers.In addition, disttrict inspectyors want to see test record books hence tyhe policy on assessment needs to be traansformed and include other assesment procedures.

The reality in many classrooms is that teachers are demotivated,feel enslaved and resigned because of poor remuneration."They give us more but no money,we have a ot of records and they over burden us with this animal PLAP.We have been doing remedial work so its just they want to keep us busy with their demands which torture us." Teachers indiocated that the timetable is full and they have a very big work load because they are required to have as many as seven record book and now they have been ordered to have the PLAP. One school head reorted that he doubts whether teacher a fully committed in implememtation of the programme since they just say many of the pupils mastered the concepts.Negative teacher perceptions have been found to be caused by poor working condition,remunertions and the top- down imposition of policies(Kurebwa and Nyaruwata,2012 and Kaputa,2009).

Results from in depth interviews indicated that teachers need in-servicing workshops thatpopularise valternative assessment procedures."Teachers need workshops which are well resourced with reading materials and handouts because note-taking has its weaknesses."

\section{CONCLUSIONS AND RECOMMENDATIONS}

The research can conclude that the WRAT used for identifying the level of performance of leaners does not provie adequate vinformation about the leaner's problem other than just norming them.The research recommeds that locally esigned tests which a tailor made to suit the needs of the teachers need to be used so that taechers cajn fully comprehend the nature of leaners problems.

The researchers can conclude that the assessment system currently being used being used in schools hinders the effective implementation of PLAP.There is need for structural change of the suggested vway of recording the evaluations since it does not give adequate informatipon abouit tthe learner's performance.It is clear that with the current appalling working conditions of many teachers resort to just fulfilling the demands of their superiors without effectively implementing the programme.It is a well documented fact that the plight of teachers especially 
in rural areas is dire hence the government should incentives teachers so thatthey become committed.Teachers had shallow knowledge of the assessment techniques espoused in the PLAP teachers manual hence the ministry should create a team of expect teachers in the area of assessment who go to each school to inservice teachers and demonstrate how these methods can be used.Worksshops are time and cost effective however there is need for demonstrations from the team of experts so that techers can follow.

The evaluation component of PLAP teachers' record books does not communicte useful information of learner performance and the decision taken by the teachers. There is need to bgive teachers the autonomy to full give a judgement basing on the information that thyey have collected.

\section{References}

Gearheart,BR and LittonF.R (1975) The Trainable Retarded.A foundations Approach. Saint Louis:CV Mosby.

Mufanechiya,A;Mandiudza,L;Mufanechiya,T and Jinga,N (2012) Challenges faced by Zimbabwean primary schools that perform poorly at grade seven level:A case for Chivi bottom ten schools in Masvingo.Education Research Journal 2(10)

Harlen (2012) Developing Policy, Principles and Practice in Practice in Primary School Science Assessment.London:Nullifield.

National Council for Curriculum and Assessment (2004) Assessment in Primary schools.

Mansell,W and James,M (2009) Assessment in Schools.Fit for Purose? A Commentary by the Teaching and Research Programme.London:T.R.P and E.S.R.C.

Kurebwa, M and Nyaruwata, L.T (2013) Assessment Challenges in the Primary Schools.A Case of Gweru Urban Schools. Greener Journal of Educational Research.VOL.3(7).

Dikli (2003) Assessment at a Distance:The Turkish Online Journal of Educational Technology.Vol 2(3:3).

Hamayan,E.V (1995) Approaches to Alternative Assessment: Annual Review of Applied Linguistics.Vol.15

Nkoma,E (2014) Performance Lag Adress Programme (PLAP): Teachers Perceptions and Pedagogical Approaches in Mutare Urban (former Group B Primary Schools.

Zindi,F (1994) Towards bthe standardisation of the WISC-R fopr Early Childhood Assessment in Zimbabwe.IFE PSYCHOLOGIA.Vol.2(2) 